\title{
KINERJA ANGKUTAN UMUM AG (ARJOSARI - GADANG) PADA MASA PANDEMI COVID-19 KOTA MALANG
}

\author{
Rifky Aldila Primasworo ${ }^{1}$ dan Andreas Joni ${ }^{2}$ \\ ${ }^{1}$ Teknik Sipil, Fakultas Teknik, Universitas Tribhuwana Tunggadewi, Malang \\ ${ }^{2}$ Teknik Sipil, Fakultas Teknik, Universitas Tribhuwana Tunggadewi, Malang \\ E-mail: Rifky.unitrimalang@gmail.com,andreasjoni96@gmail.com.
}

\begin{abstract}
ABSTRAK: Angkutan umum penumpang yang disebut juga sebagai angkutan kota adalah salah satu sarana transportasi yang digunakan untuk melayani aktifitas masyarakat di Kota Malang. Pada saat Pandemi, volume jumlah penumpang pengguna jasa angkotan umum penumpang semakin hari semakin berkurang, namun pada dasarnya angkutan umum penumpang masih dibutuhkan oleh masyarakat Kota Malang dalam melakukan aktifitas sehari hari. Dalam pelayanannya waktu tempuh angkutan umum penumpang jalur $\mathrm{AG} \pm 1$ jam dengan jarak tempuh $\pm 16 \mathrm{~km}$. Adapun Tujuan dari penelitian ini adalah untuk mengetahui tingkat pelayanan angkutan umum penumpang trayek AG (Terminal Arjosari-Gadang) selama masa pandemi covid-19. Metode analisis data yang dipergunkan dalam penelitian ini yaitu metode deskriptif dan kuantitatif. Survey yang dilakukan menggunakan survey statis,dinamis dan wawancara atau interview. Hasil penelitian didapatkan bahwa Parameter kinerja lalu lintas yang perlu ditingkatkan selama pandemi covid-19 meliputi frekuensi angkutan umum, jumlah kendaraan yang beroperasi, waktu pelayanan (awal dan akhir waktu pelayanan).
\end{abstract}

Kata Kunci : angkutan umum, kinerja, pandemi

\section{PENDAHULUAN}

Kota Malang merupakan kota terbesar kedua di Jawa Timur setelah Kota Surabaya dan merupakan salah satu kota yang memiliki posisi sangat strategi secara geografis, selain itu Kota Malang terkenal dengan semboyan Tri Bina Citra yaitu sebagai Kota Pendidikan, Kota Industri dan Kota Parawisata yang mencerminkan profil potensi ekonomi Kota Malang. Padatnya kegitan berbanding lurus dengan perkembangannya pergerakan masyarakat yang menuntut kebutuhan transportasi yang lebih berkembang. Perkembangan tersebut menghadapkan Kota Malang pada keseimbangan antara supply dan demand, meningkatkanya jumlah pengguna kendaraan pribadi akibat rendahnya tingkat pelayanan dan Kinerja Angkutan Umum.

Angkutan umum penumpang di Kota Malang yang disebut angkutan kota adalah salah satu sarana transportasi yang digunakan untuk melayani aktifitas masyarakat di Kota Malang. Meskipun saat ini volume jumlah penumpang pengguna jasa angkotan umum penumpang yang semakin hari semakin berkurang, namun angkotan umum penumpang masih dibutuhkan oleh masyarakat kota malang dalam melakukan aktifitas sehari hari.

Permasalahan yang terjadi adalah dari data di lapangan ternyata kondisi angkutan umum penumpang AG (terminal arjosari-Gadang/Hamid Rusdi) mulai mencemaskan karena kurangnya penumpang yang berminat menggunakan jasa angkutan umum penumpang AG. hal ini di karena adanya kendaraan online seperti Greb atau Gojek, dan masyarakat Kota Malang banyak yang mempuyai kendaraan pribadi (motor/ mobil). Sedangkan jumlah kendaraan yang beroperasi di trayek AG sangat besar, sehingga berpengaruh terhadap pendapatan angkutan umum penumpang $\mathrm{AG}$, waktu tempuh angkutan umum penumpang jalur $A G \pm 1$ jam dengan jarak tempuh $\pm 16 \mathrm{~km}$.

Tujuan dari penelitian ini adalah untuk mengetahui tingkat kinerja angkutan umum AG pada masa panemi di tahun 2020 dan memberikan solusinya dalam meningkatkan kinerja angkutan umum.

\section{METODE PENELITIAN}

A. Diagram alir Penelitian

Dapat dilihat pada Gambar 1

B. Lokasi dan Waktu Survey

Lokasi penelitian angkutan umum penumpang trayek AG (Terminal Arjosari-Terminal Hamid Rusdi/Gadang) Kota Malang dengan panjang rute adalah $\mathrm{AG} \pm 16 \mathrm{~km}$. Untuk lebih jelasnya dapat dilihat pada Gambar 2.

\section{METODE PENGUMPULAN DATA}

Pengambilan data diperoleh dari data primer yaitu data yang diproleh dengan cara pengamatan langsung dilapangan. Pengumpulan data dilakukan semala tiga (3) hari yaitu pada hari kerja dan hari libur dari pukul 07: 00-17:00, karena jam tersebut diasumsikan berlangsungnya kegiatan penduduk dan data sekunder. Untuk lebih jelasnya dapat dilihat pada Tabel 1.

Tabel 1 Kebutuhan Data Sekunder

\begin{tabular}{|l|l|l|}
\hline No & \multicolumn{1}{|c|}{ Kebuhan Data } & \multicolumn{1}{c|}{ Instansi } \\
\hline 1 & Jumlah armada trayek AG & Dinas perhubungan \\
\hline 2 & Rute angkutan trayek AG & Dinas perhubuangan \\
\hline 3 & Panjang rute trayek AG & Dinas perhubungan \\
\hline 4 & Jumlah rit trayek AG & Dinas perhubungan \\
\hline 5 & Jam operasi trayek AG & Perum angkutan \\
\hline
\end{tabular}

Metode pengumpulan data meliputi data primer yaitu survey statis adalah survey yang dilakukan pada titik tertentu dengan mengamiati dan mencatat informasi dari setiap angkutan umum trayek Terminal ArjosariGadang/terminat hamid rusdi, survey dinamis adalah dengan cara menaiki angkutan umum rute Terminal Arjosari - Gadang/terminal hamid rusdi. Survey dinamis ini untuk jumlah data naik dan data turun penumpang, waktu keberagkatan dari terminal keberangkatan dan waktu angkutan tiba di terminal tujuan dan wawancara. 

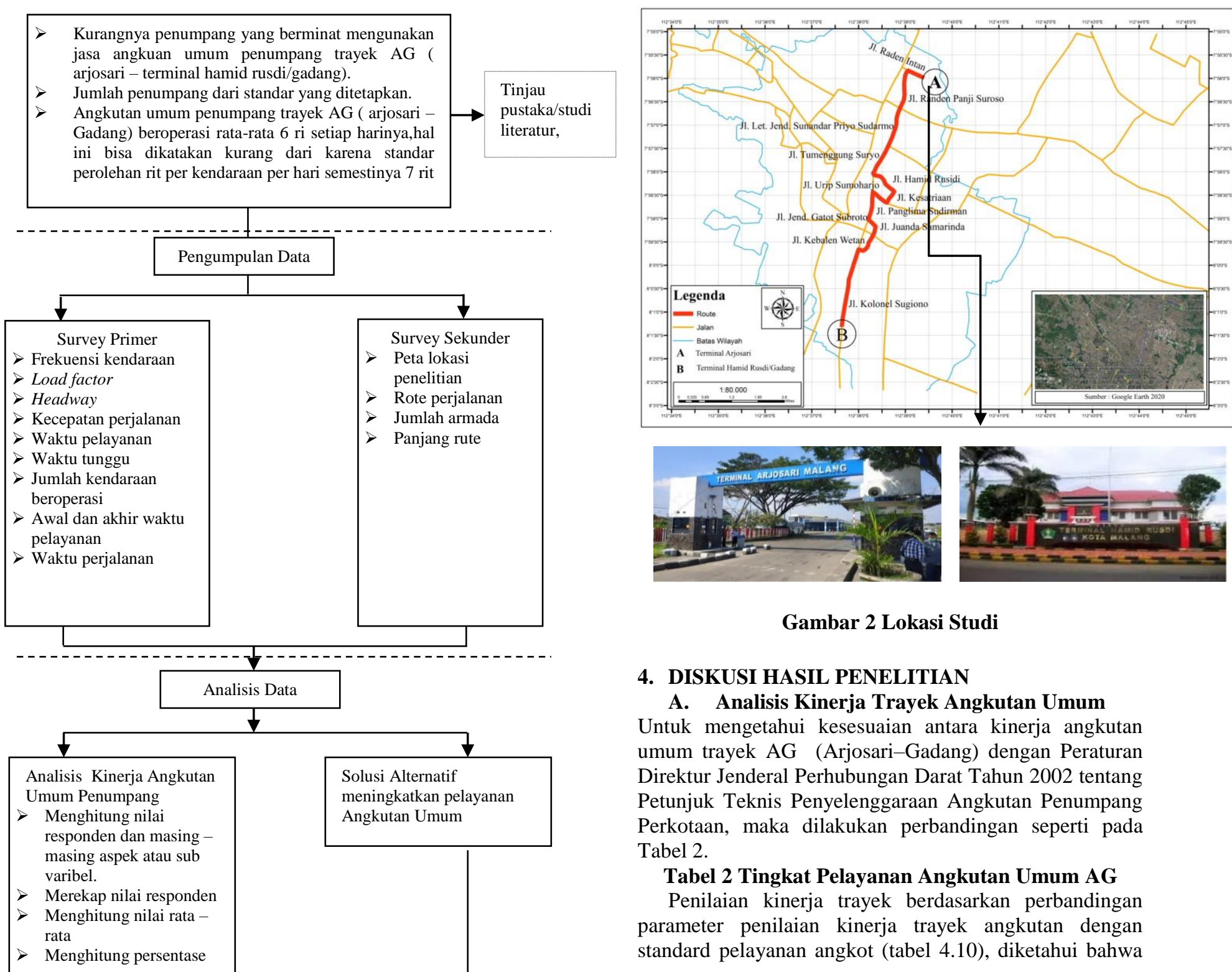

\section{Gambar 2 Lokasi Studi}

\section{DISKUSI HASIL PENELITIAN}

\section{A. Analisis Kinerja Trayek Angkutan Umum}

Untuk mengetahui kesesuaian antara kinerja angkutan umum trayek AG (Arjosari-Gadang) dengan Peraturan Direktur Jenderal Perhubungan Darat Tahun 2002 tentang Petunjuk Teknis Penyelenggaraan Angkutan Penumpang Perkotaan, maka dilakukan perbandingan seperti pada Tabel 2.

\section{Tabel 2 Tingkat Pelayanan Angkutan Umum AG}

Penilaian kinerja trayek berdasarkan perbandingan parameter penilaian kinerja trayek angkutan dengan standard pelayanan angkot (tabel 4.10), diketahui bahwa

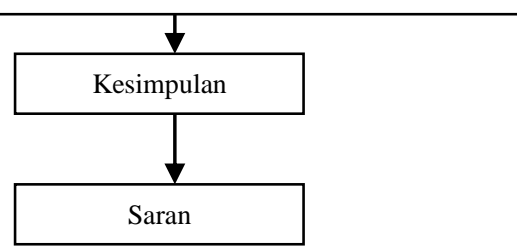

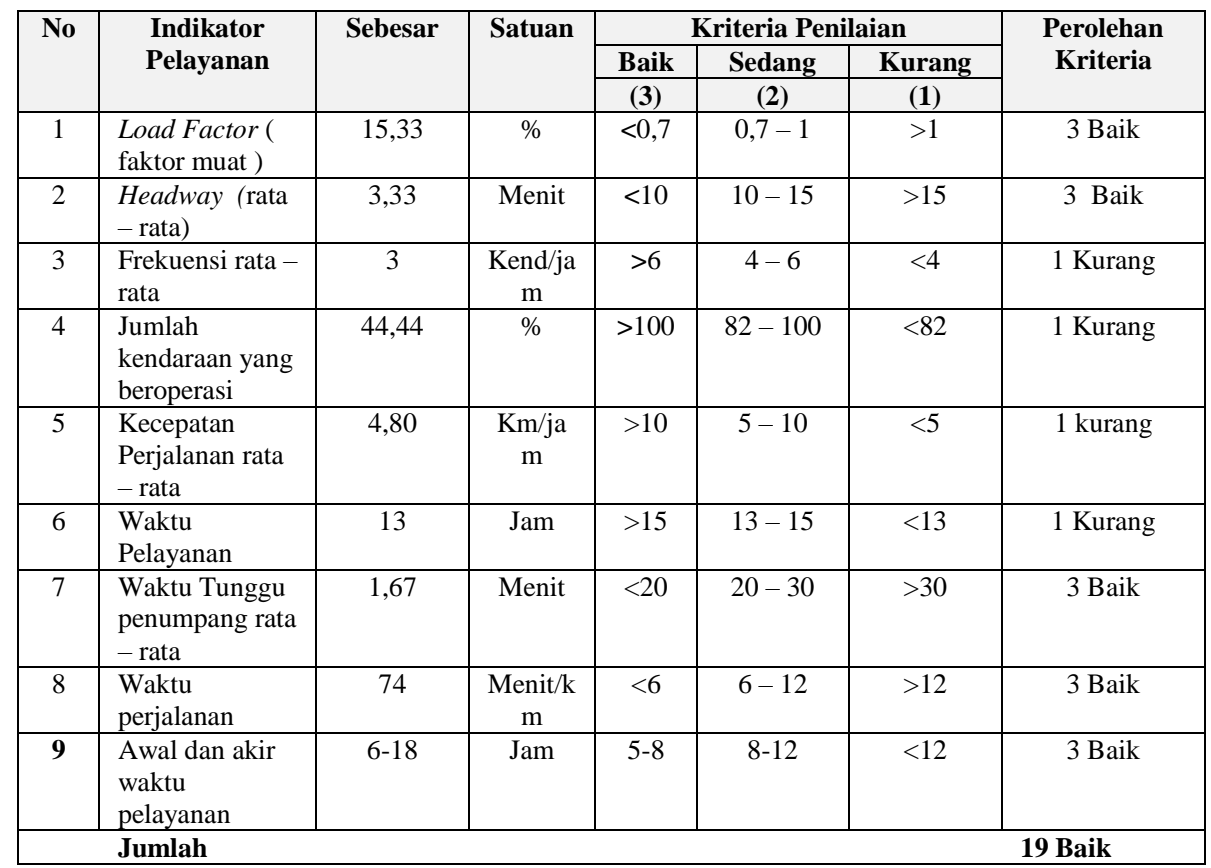


penilaian Load Factor, headway, frekuensi, Jumlah kendaraan yang beroperasi, Kecepatan perjalanan, waktu pelayanan, waktu tunggu penumpang, dan waktu perjalanan, Awal dan akhir waktu pelayanan pada angkutan umum penumpang trayek AG (Arjosari Gadang) termasuk kategori baik sesuai standard penilaian.

Sementara parameter frekuensi, jumlah kendaraan yang beroperasi, waktu pelayanan, Awal dan akhir waktu pelayanan termasuk kategori kurang pada standard penilaian angkutan umum berdasarkan standard Dishub. Dan untuk load factor, kecepatan perjalanan, dan waktu perjalanan termasuk kategori baik. Secara keseluruhan diperoleh nilai 19. Nilai tersebut diartikan bahwa secara keseluruhan tingkat pelayanan angkutan umum penumpang trayek AG (Arjosari - Gadang) berdasarkan standard pelayanan angkutan umum berdasarkan nilai bobot termasuk kriteria "Baik". Dari keseluruhan penilaian terhadap moda dan trayek angkutan, pada trayek AG (Arjosari - Gadang) diketahui bahwa kinerja pelayanan trayek yang tidak berjalan sesuai ketetapan tetap memberikan layanan yang baik walaupun parameter, frekuensi, jumlah kendaraan yang beroperasi, waktu pelayanan, dan Awal dan akhir waktu pelayanan termasuk kategori kurang.

\section{Penelitian Sebelum Pendemi}

Untuk mengetahui kesesuaian antara kinerja angkutan umum trayek AG ( Arjosari - Gadang ) dengan Peraturan Direktur Jenderal Perhubungan Darat Tahun 2002 tentang Petunjuk Teknis Penyelenggaraan Angkutan Penumpang Perkotaan, maka dilakukan perbandingan.

Penilaian kinerja trayek berdasarkan perbandingan parameter penilaian kinerja trayek angkutan dengan standard pelayanan angkot, diketahui bahwa penilaian Load Factor, headway, frekuensi, Jumlah kendaraan yang beroperasi, Kecepatan perjalanan, waktu pelayanan, waktu tunggu penumpang, dan waktu perjalanan pada angkutan umum penumpang trayek AG (Arjosari Gadang) termasuk kategori baik sesuai standard penilaian.

Sementara parameter jumlah kendaraan yang beroperasi, load factor, waktu pelayanan, termasuk kategori kurang pada standard penilaian angkutan umum berdasarkan standard Dishub. Dan untuk Frekuensi,headway,kecepatan perjalanan, dan waktu perjalanan termasuk kategori baik. Secara keseluruhan diperoleh nilai 20. Nilai tersebut diartikan bahwa secara keseluruhan tingkat pelayanan angkutan umum penumpang trayek AG (Arjosari - Gadang) berdasarkan standard pelayanan angkutan umum berdasarkan nilai bobot termasuk kriteria "Baik". Dari keseluruhan penilaian terhadap moda dan trayek angkutan, pada trayek AG (Arjosari - Gadang) diketahui bahwa kinerja pelayanan trayek yang tidak berjalan sesuai ketetapan tetap memberikan layanan yang baik walaupun parameter jumlah kendaraan yang beroperasi, waktu pelayanan termasuk kategori kurang.

Perbandigan antara penelitian sebelum dan masa pendemi covid 19 pada trayek AG (Arjosari - Gadang). Adalah penelitian saat covid 19 load factor 15,33\%,Headway 3,33 Menit, Frekuensi 3 kend/jam,
Jumlah kendaraan yang beroperasi $44,44 \%$, Waktu perjalanan 74 Menit/km Kecepatan perjalanan 4,80 $\mathrm{Km} / \mathrm{jam}$, Waktu pelayanan 13 jam dan Awal dan Akhir waktu pelayanan 6-18 jam. Waktu tunggu 1,67 Menit. Nilai tersebut diartikan bahwa secara keseluruhan tingkat pelayanan angkutan umum penumpang trayek AG (Arjosari - Gadang) berdasarkan standard pelayanan angkutan umum berdasarkan nilai bobot termasuk kriteria "Baik". Sedangkan sebelum covid 19 Adalah Load Factor 189,15\% , Headway 0,88 Menit, frekuensi $62 \mathrm{kend} / \mathrm{Jam}$, jumlah kendaraan yang beroperasi $53 \%$, kecepatan perjalanan 16,44 Km/jam, waktu pelayanan $12 \mathrm{Jam}$, Waktu Tunggu 2 Menit dan waktu perjalanan 58 Menit $/ \mathrm{km}$. Nilai tersebut diartikan bahwa secara keseluruhan tingkat pelayanan angkutan umum penumpang trayek AG (Arjosari - Gadang) berdasarkan standard pelayanan angkutan umum berdasarkan nilai bobot termasuk kriteria "Baik".

\section{B. Solusi Alternatif Untuk Meningkatkan Kinerja Pelayanan Angkutan Umum trayek AG (Arjosari- Gadang )}

Setelah mengetahui permasalahan kinerja pelayanan angkutan umum penumpang yang ada, selanjutnya dapat ditentukan solusi alternatif untuk meningkatkan kinerja pelayanan angkutan umum trayek AG (Arjosari- Gadang). Adapun solusi alternatif yang diusulkan penulis terdapat pada Tabel 3 :

Tabel 3 Solusi Masala Dari Parameter Kinerja Angkutan Umum

\begin{tabular}{|c|c|c|c|c|}
\hline No & $\begin{array}{c}\text { Parameter } \\
\text { Kinerja } \\
\text { Angkutan }\end{array}$ & Masalah & Solusi & Output \\
\hline 1 & Frekuensi & $\begin{array}{l}\text { Frekuinsi } \\
\text { terlalu } \\
\text { singkat } \\
\text { (kurang) }\end{array}$ & $\begin{array}{l}\text { Mengatur } \\
\text { kembali } \\
\text { waktu } \\
\text { frekuensi } \\
\text { - waktu } \\
\text { beropera } \\
\text { si } \\
\text { - waktu } \\
\text { perjalana } \\
\text { n }\end{array}$ & $\begin{array}{l}\text { Frekuensi sesuai } \\
\text { standar yang } \\
\text { ditentukan oleh } \\
\text { Peraturan Direktur } \\
\text { Jenderal Perhubungan } \\
\text { Darat Tahun } 2002 \\
\text { tentang Petunjuk } \\
\text { Teknis } \\
\text { Penyelenggaraan } \\
\text { Angkutan } \\
\text { Penumpang } \\
\text { Perkotaan }\end{array}$ \\
\hline 2 & $\begin{array}{l}\text { Jumlah } \\
\text { kendaraan } \\
\text { yang } \\
\text { beroperasi }\end{array}$ & $\begin{array}{l}\text { Jumlah } \\
\text { kendaraan } \\
\text { banyak } \\
\text { tetapi yang } \\
\text { beroperasi } \\
\text { optimal } \\
\text { kurang }\end{array}$ & $\begin{array}{l}\text { Mengatur } \\
\text { kembali } \\
\text { kendaraan } \\
\text { yang } \\
\text { beroperasi } \\
\text { - waktu } \\
\text { kendaraa } \\
n \\
\text { beropera } \\
\text { si } \\
\text { - standar } \\
\text { rit per } \\
\text { hari }\end{array}$ & $\begin{array}{l}\text { Jumlah kendaraan } \\
\text { yang beroperasi } \\
\text { sesuai standar yang } \\
\text { ditentukan oleh } \\
\text { Peraturan Direktur } \\
\text { Jenderal Perhubungan } \\
\text { Darat Tahun } 2002 \\
\text { tentang Petunjuk } \\
\text { Teknis } \\
\text { Penyelenggaraan } \\
\text { Angkutan } \\
\text { Penumpang } \\
\text { Perkotaan }\end{array}$ \\
\hline 3 & $\begin{array}{l}\text { Waktu } \\
\text { pelayanan }\end{array}$ & $\begin{array}{l}\text { Waktu } \\
\text { pelayaanan } \\
\text { masi } \\
\text { kurang } \\
\text { standsar }\end{array}$ & $\begin{array}{l}\text { Mengatur } \\
\text { kembali } \\
\text { waktu } \\
\text { pelayanan } \\
\text { - mengatu } \\
\text { r waktu } \\
\text { istrahat } \\
\text { - waktu } \\
\text { kendaraa } \\
\text { n yang } \\
\text { beropera } \\
\text { si }\end{array}$ & $\begin{array}{l}\text { Jumlah kendaraan } \\
\text { yang beroperasi } \\
\text { sesuai standar yang } \\
\text { ditentukan oleh } \\
\text { Peraturan Direktur } \\
\text { Jenderal Perhubungan } \\
\text { Darat Tahun } 2002 \\
\text { tentang Petunjuk } \\
\text { Teknis } \\
\text { Penyelenggaraan } \\
\text { Angkutan } \\
\text { Penumpang } \\
\text { Perkotaan }\end{array}$ \\
\hline
\end{tabular}




\begin{tabular}{|c|c|c|c|c|}
\hline \multicolumn{5}{|c|}{ Lanjutan Tabel 3} \\
\hline 4 & $\begin{array}{l}\text { Awal dan } \\
\text { akhir waktu } \\
\text { pelayana }\end{array}$ & $\begin{array}{l}\text { Waktu } \\
\text { pelayanan } \\
\text { masih } \\
\text { kurang } \\
\text { standar }\end{array}$ & $\begin{array}{l}\text { Mengatur } \\
\text { kembali } \\
\text { waktu } \\
\text { pelayanan } \\
\text { - waktu } \\
\text { operasi } \\
\text { - waktu } \\
\text { istrahat }\end{array}$ & $\begin{array}{l}\text { Awal dan akhir waktu } \\
\text { pelayanan yang } \\
\text { beroperasi sesuai } \\
\text { standar yang } \\
\text { ditentukan oleh } \\
\text { Peraturan Direktur } \\
\text { Jenderal Perhubungan } \\
\text { Darat Tahun 2002 } \\
\text { tentang Petunjuk } \\
\text { Teknis } \\
\text { Penyelenggaraan } \\
\text { Angkutan } \\
\text { Penumpang } \\
\text { Perkotaan }\end{array}$ \\
\hline
\end{tabular}

Sumber:Hasil Analisis 2020

\section{UCAPAN TERIMA KASIH}

Terima kasih kepada Allah SWT yang memberikan kesempatan, kesehatan dan kelancaran proses penelitian, Ucapan terima kasih juga kepada Dinas Perhubungan Kota Malang, Bappeda Kota Malang yang telah diperbolehkan untuk mengambil data dan melakukan penelitian. Tak lupa kepada semua pihak yang telah membantu dalam proses penelitian dari awal sampai dengan akhir.

\section{KESIMPULAN}

1) Hasil kinerja dari angkutan masa pendemi covid 19 trayek AG (Arjosari- Gadang ) antara lain : Jumlah penumpang rata-rata $=2$, Load factor $=$ $15,33 \%$, kecepatan perjalanan $=4,80 \mathrm{~km} / \mathrm{jam}$, waktu antara (Headway) $=3,33$ menit, waktu perjalanan $=4,56$ menit $/ \mathrm{km}$, waktu pelayanan $=13$ jam/hari, jumlah kendaraan yang beroperasi = $44,44 \%$, waktu tunggu penumpang $=1,67$ menit dan awal dan akhir pelayanan $=06: 30-18: 00$ WIB. Dengan kategori penilaian BAIK. Adapun beberapa tingkat pelayanan yang keriteria kurang seperti waktu pelayanan, dan Awal dan akhir waktu pelayanan. Hasil kinerja dari angkutan sebebelum covid 19 trayek AG (Arjosari- Gadang) antara lain : Load factor $=189,15 \%$, kecepatan perjalanan $=4,80 \mathrm{~km} / \mathrm{jam}$, waktu antara (Headway) $=0,88$ menit, Frekuensi $62 \mathrm{ken} / \mathrm{jam}$, waktu perjalanan $=16,44$ menit $/ \mathrm{km}$, waktu pelayanan $=12 \mathrm{jam} /$ hari, jumlah kendaraan yang beroperasi $=53 \%$, waktu tunggu penumpang $=2$ menit. Dengan kategori penilaian BAIK. walaupun ada beberapa tingkat pelayanan yang kriteria kurang seperti Load Factor, jumlah kendaraan yang beroperasi, waktu pelayanan.

2) Solusi Alternatif Kinerja Angkutan Umum

a. Frekuensi

Mengatur kembali waktu frekuinsi dengan

cara waktu beroperasi,waktu perjalanan

b. Jumlah Kendaraan yang Beroperasi

Mengatur kembali kendaraan yang

beroperasi dengan cara waktu kendaraan

beroperasi, standar rit per hari c. Waktu Pelayanan

Mengatur kembali waktu pelayanan dengan cara mengatur waktu istirahat, waktu kendaraan.

d. Awal dan Akir Waktu Pelayanan Mengatur kembali Awal dan Akir Waktu Pelayanan dari segi waktu beroperasi dan waktu istirahat.

\section{DAFTAR PUSTAKA}

Asikin, Muslich Zainal.2001. Sistem Manajemen Transportasi Kota. Yogyakarta : Penerbit UGM.

Undang - undang No. 22 tahun 2009, Tentang Lalu Lintas dan Angkutan Jalan. Peraturan Pemerintah Nomor 74 Tahun 2014 Tentang Angkutan Jalan.

Keputusan Direktorat Jenderal Perhubungan Darat Nomor SK. 678/AJ. 206/DRJD/2002. Tentang Pedoman Teknis Penyelenggaraan Angkutan Umum Penumpang Umum Diwilayah Perkotaan Dalam Trayek Tetap dan Teratur.

Direktorat Jenderal Perhubungan Darat,(2002), Pedoman Teknis Penyelengaraan Angkutan Umum di Wilayah Perkotaan dalm Trayek Tetap dan Teratur.

Direktorat Jenderal Perhubungan Darat, (2002), Panduan Pengumpulan Data Angkutan Umum Perkotaan.

Direktorat Jenderal Perhubungan Darat,(1996), Pedoman Teknis Penyelenggaraan Angkutan Penumpang Umum di Wilayah Perkotaan dalam Trayek Tetap dan Teratur.

Direktorat Jenderal Perhubungan Darat, (1995), Мепијu Lalu Lintas dan Angkutan Jalan Yang Tertip.

Morlok, E.K,(1978), Pengantar Teknik dan Perencanaan Transportasi, Terjemahan oleh Johan Kelanaputra Hainim 1985. Penerbit Erlangga, Jakarta.

Nasution, H.M.N., (2008), Manajemen Transportasi, Ghalia Indonesia, Jakarta. Tamin, O.Z, (1997), Perencanaan dan Permodelan Transportasi, penerbit ITB, Bandung.

Warpani, Suwardjoko. (2002), Pengolahan Lalu Lintas dan Angkutan Jalan, Penerbit ITB, Bandung. 